\title{
Experimental Research on Dynamic Compaction Parameters of Deep Gravel Filling Foundation
}

\author{
Kaining $\mathrm{Yu}^{1, \mathrm{a}}$, Hao $\mathrm{Fu}^{1, \mathrm{~b}}, \mathrm{Min}_{\mathrm{Zhao}}^{2, \mathrm{c}}$ Jian $\mathrm{Li}^{3, \mathrm{~d}}$ \\ ${ }^{1}$ Shijiazhuang University of Economics, China \\ ${ }^{2}$ Qingdao Geotechnical Investigation and Surveying Research Institute, China \\ ${ }^{3}$ Beijing New Oriental Star Petrochemical Engineering Co.,Ltd, China \\ ayukn2000@sjzue.edu.com, bhnzmdfh@163.com, 'zhaomin3830@sina.com, d3069694@qq.com
}

\begin{abstract}
Keywords: ramming energy; gravel filling; vibrating velocity; rayleigh wave velocity; effective reinforcement depth; correction factor

Abstract. In order to study the reinforcement process and effect of different energy levels of dynamic compaction,three energy levels of dynamic compaction experiments with 3000,6000,10000 KN•m are proceed on deep gravel filling foundation.Get datas of ramming settlement, pore water pressure,vibrating velocity during dynamic compaction and datas of rayleigh wave test, super-heavy dynamic pentration test, shallow plate loading test after dynamic compaction. Analysis of datas,conclude that the first three cumulative ramming settlement accounts for $50 \%$ of the total;For deep gravel filling foundation, can't consider the dissipation of excess pore water pressure,can continuously construct.;The spread of vibration in the soil,tangential velacity is maximum,followed by the vertical velocity and the radial velocity is minimum,the safety distance of general civil construction is 20 to 40 meters,the safety distance of industrial and commercial buildings is 15 to 30 meters, and advice the selection of safe distance should be subject to the last time ramming; The rayleigh wave's velocity of surface soil is decreased with high energy dynamic compaction;. The effective reinforcement depths of $3000,6000,10000 \mathrm{KN} \cdot \mathrm{m}$ are 6,9 and 12 meters, correction factor of menard formula is 0.35 to 0.41 .
\end{abstract}

\section{Introduction}

In recent years,scholars have acquired many achievements for dynamic compaction of gravel filling foundation [1,2,3,4],but these studies are focused on low level of ramming energy, research for high level of ramming energy is less. In recent years, with the rapid development of coastal city's infrastructures, caused a lot of gravel filling projects, the requirements of foundation treatment are higher and higher. High energy level of dynamic compaction is gradually applied especially in gravel filling foundation[5,6,7,8].

Many scholars study the reinforcement process and effect of dynamic compaction. Tiehong Wang etc [9] analye the test datas of pore water pressure in the gravel filling foundation with $10000 \mathrm{KN} \bullet \mathrm{m}$, get the appropriate interval time of the first and the second ramming is $4 \mathrm{~d}$, the appropriate interval time of the second and the third ramming is $7 \mathrm{~d}$, Shuaijun Zhao etc [10]test the strengthening effect of gravel filling foundation after the ramming energy of $10000 \mathrm{KN} \cdot \mathrm{m}$ by mean of rayleigh wave testing,get the results that 0 to 1 meter depth's velocity decreases , but the 1-8 meters depth's wave velocity increasesGuanbao Ye etc [11] test the reinforcement effect of different mixture filling foundation with $4000 \mathrm{KN} \bullet \mathrm{m}$ by single-hole wave velocity testing,conclue that the reinforcement effect of the argillaceous siltstone and tuff stone's volume ratio of 1:1 is better than the volume ratio of 1:2. Changming Hu etc [12] carry out the field test of collapsible loess foundation, analyze the average of ramming settlement and the soil's physical properties, get the best ramming times, stop criteria and effective reinforcement depths of the ramming energy of 2000,3000,6000 $\mathrm{KN} \cdot \mathrm{m}$. From the research status, Most studies focus on the energy level that below $6000 \mathrm{KN} \bullet \mathrm{m}$,though few study focus on the high energy level that above the $6000 \mathrm{KN} \bullet \mathrm{m}$,but lack of comparative study between high and low energy level ,especially for the deep gravel filling foundation. 
So in view of the existing problems,select three trial ramming areas whose soil conditions are similar.carryout field test about $3000,6000,10000 \mathrm{KN} \cdot \mathrm{m}$. Accurately montior ramming settlement,pore water pressure,vibrating velocity in the process. Test the reinforcement effect by the rayleigh wave test, super-heavy dynamic penetration test, shallow plate loading test, analyze the change rules of different datas, evaluate the reinforcement effect of different ramming energy, Can provide a reference for construction parameters' choice about analogously dynamic compaction.

\section{The research method and testing data collection}

Ramming energy and arrangement of tamping points. The filling thickness of ground is about 12 metres, in main of gravel. There are three trial ramming areas,each covers an area of900 Square meters. Hammers'underside are circular. The design requires that characteristic value of foundation' carrying capacity is't less than $150 \mathrm{kpa}$. The areas' construction parameters are shown in Table 1.

Table 1 Trial ramming areas' construction parameters

\begin{tabular}{|c|c|c|c|c|}
\hline Zone & $\begin{array}{l}\text { Single-point's ramming } \\
\text { energy }(\mathrm{kN} \cdot \mathrm{m})\end{array}$ & $\begin{array}{l}\text { Distance of } \\
\text { ramming } \\
\text { points }(\mathrm{m})\end{array}$ & $\begin{array}{l}\text { The full } \\
\text { ramming } \\
\text { energy }(\mathrm{kN} \cdot \mathrm{m})\end{array}$ & Ramming method \\
\hline $\begin{array}{l}\text { The first } \\
\text { area }\end{array}$ & 3000 & $5 \times 5$ & 1500 & $\begin{array}{l}2 \text { times of points } \\
\text { ramming and } 1 \text { time of } \\
\text { full ramming }\end{array}$ \\
\hline $\begin{array}{l}\text { The } \\
\text { second } \\
\text { area }\end{array}$ & 6000 & $6 \times 6$ & 1500 & $\begin{array}{l}2 \text { times of points } \\
\text { ramming and } 1 \text { time of } \\
\text { full ramming }\end{array}$ \\
\hline \multirow{2}{*}{$\begin{array}{l}\text { The third } \\
\text { area }\end{array}$} & $\begin{array}{l}\text { 10000(The 1st and 2nd } \\
\text { times ramming ) }\end{array}$ & \multirow{2}{*}{$10 \times 10$} & \multirow{2}{*}{1500} & \multirow{2}{*}{$\begin{array}{l}3 \text { times of points } \\
\text { ramming and } 1 \text { time of } \\
\text { full ramming }\end{array}$} \\
\hline & $\begin{array}{l}\text { 3000(The 3rd } \\
\text { timeramming) }\end{array}$ & & & \\
\hline
\end{tabular}

Monitoring arrangements. The monitoring includes: ramming settlement, pore water pressure,vibrating velocity during dynamic compaction. According to the change of vibration velocity ,determine the scope of dynamic compaction on the surrounding environment. According to the dissipation situation of pore water pressure, determine the ramming interval time.

Testing arrangements.Test the reinforcement effect of trial ramming areas after dynamic compaction by rayleigh wave test,super-heavy dynamic pentration test, shallow plate loading test.

\section{The results and analysis}

Monitoring results and analysis of ramming settlement. Construction carries out in strict accordance with the specification[13]and manual[14]. freely choose a single-point's ramming settlement of the first time ramming in each area. The changing laws of ramming settlement along with ramming times are shown in Fig.1.

Fig.1shows that with the increase of ramming times ,the single ramming settlement gradually decreases, and the speed of decreasing gradually slows down. At last the single ramming settlement tends to a smaller value after a certain number of ramming times.For ramming energy of 3000 $\mathrm{KN} \bullet \mathrm{m}$, the first three cumulative ramming settlement accounts for $49 \%$ of the total; For ramming energy of $6000 \mathrm{KN} \bullet \mathrm{m}$, the first three cumulative ramming settlement accounts for $51 \%$ of the total; For ramming energy of $10000 \mathrm{KN} \bullet \mathrm{m}$, the first three cumulative ramming settlement accounts for $51 \%$ of the total; Through the analysis of all datas of ramming settlement in each trial ramming area, get the conclusion that the first three cumulative ramming settlement accounts for $50 \%$ of the total. With the increase of ramming times, the cumulative ramming settlement gradually increases,but the speed of increasing gradually slows down.At last the cumulative ramming settlement tends to a stable value after a certain number of ramming times. 


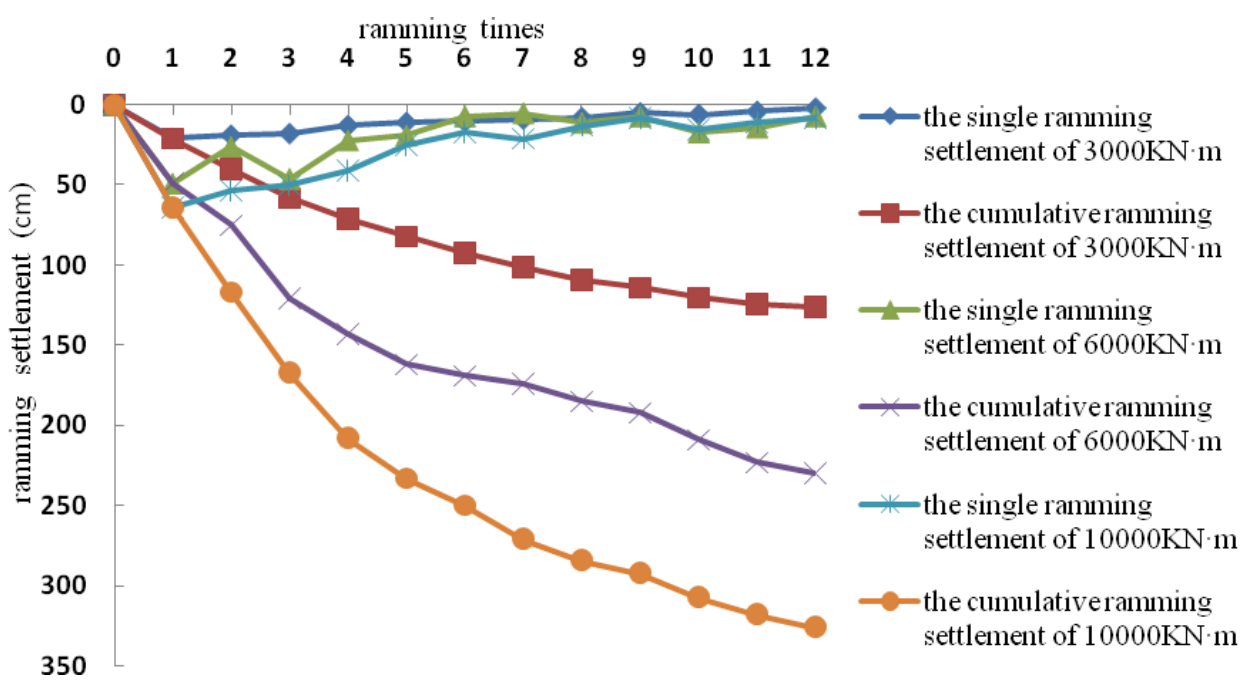

Fig. 1 The changing laws of ramming settlement along with ramming times

Monitoring results and analysis of pore water pressure.Arrange a monitoring point of pore water pressure in the center of each area, along the monitoring point lay a pore water pressure gauge every three meters, a total of four.

The monitoring results show that pore water pressure of each area changes with underground water level is obvious in the process. Dynamic compaction basically didn't affect the change of pore water pressure. Because the filling is mainly gravel,porosity is larger, pore water liquidity is better, excess pore water pressure dissipates quickly in the process. So the datas have no obvious change.

Therefore, choose a ramming point in each area,test before rising rammer, immediately test after Falling rammer, time interval is about one minute.

The continuous monitoring results show that pore water pressure increases small in the process. and dissipates quickly,back to before pressure after about 2 minutes, the change of excess pore water pressure doesn't affect dynamic compaction construction in a row.

Monitoring results and analysis of vibrating velocity. The experiment tests the vibrating velocity of 10 ,15, 20, 25, 30,40,50 and 60 metres distances of tamping points . Among them,for the area of 3000 and $10000 \mathrm{kN} \cdot \mathrm{m}$, vibrating velocity monitoring is the first time ramming point. For the trial ramming area of $6000 \mathrm{kN} \cdot \mathrm{m}$, vibrating velocity monitoring is the second time ramming point. The change rules of peak speeds with different distances are shown in Figure 2,3,4,5,6 and 7.

Figure2,3,4,5,6and 7 show that tangential velacity is maximum,followed by the vertical velocity and the radial velocity is minimum.Also the larger the ramming energy is, the more obvious the different among the speed of those three directions is , and the faster the vibration velocity of same distance is.

According to the blasting safety regulations, the safety vibration velocity of general civil building is $2 \mathrm{~cm} / \mathrm{s}$, so advice that, for $3000 \mathrm{kN} \bullet \mathrm{m}$, the safe distance is more than 20 meters,for $10000 \mathrm{kN} \bullet \mathrm{m}$, the safe distance is more than 30 meters. for $6000 \mathrm{kN} \cdot \mathrm{m}$, the safe distance is more than 40 meters.The safe distance of $6000 \mathrm{kN} \cdot \mathrm{m}$ is larger than $10000 \mathrm{kN} \cdot \mathrm{m}$, because vibrating velocity of $6000 \mathrm{kN} \cdot \mathrm{m}$ is the second time ramming, vibrating velocity of 3000 and $10000 \mathrm{kN} \cdot \mathrm{m}$ are the first time ramming. After the first time ramming ,the improvement of soil compactness is obvious, the ability of vibration transmission greatly enhances,so the testing datas of safe distance is larger than the first time ramming.So advice the selection of safe distance should be subject to the last time ramming.

In the same way ,the safety vibration velocity of Industrial and commercial buildings is $3.5 \mathrm{~cm} / \mathrm{s}$, the safe distances is 15 to 30 meters. 


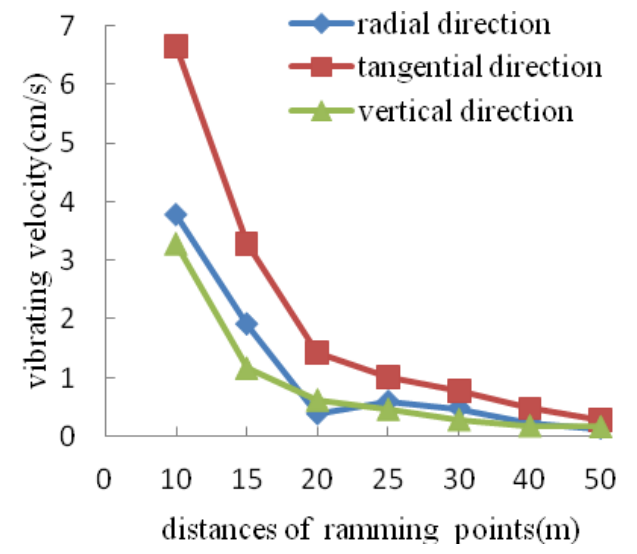

Fig.2 Vibrating velocity of $3000 \mathrm{kN} \cdot \mathrm{m}$

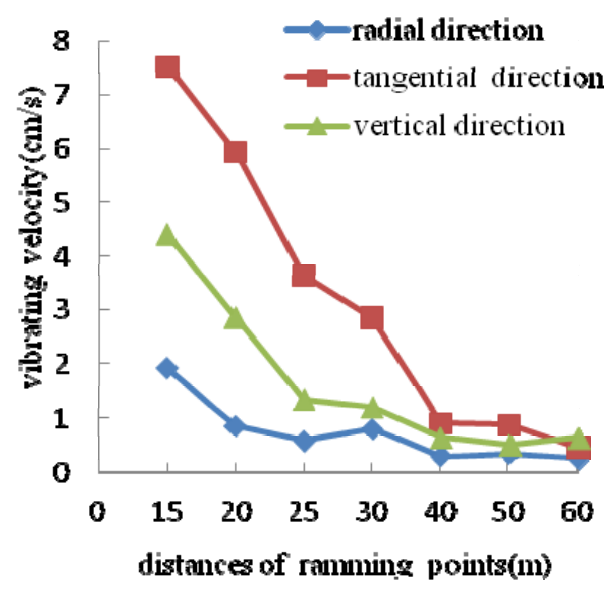

Fig. 4 Vibrating velocity of $10000 \mathrm{kN} \cdot \mathrm{m}$

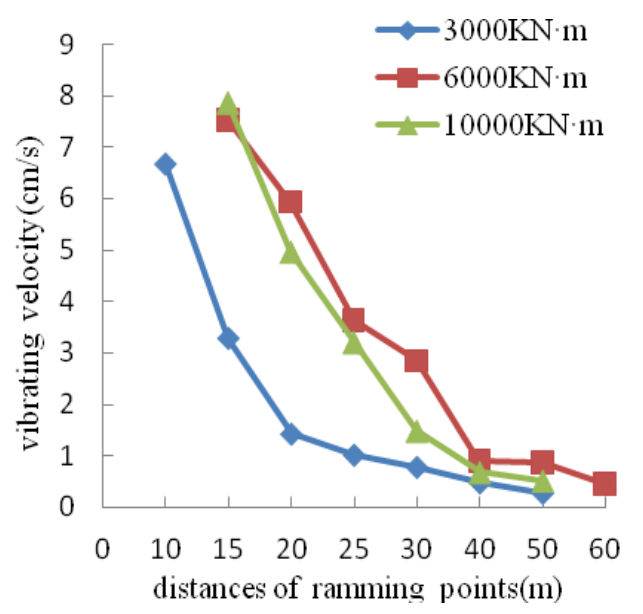

Fig. 6 Tangential vibrating velocity of different ramming energy

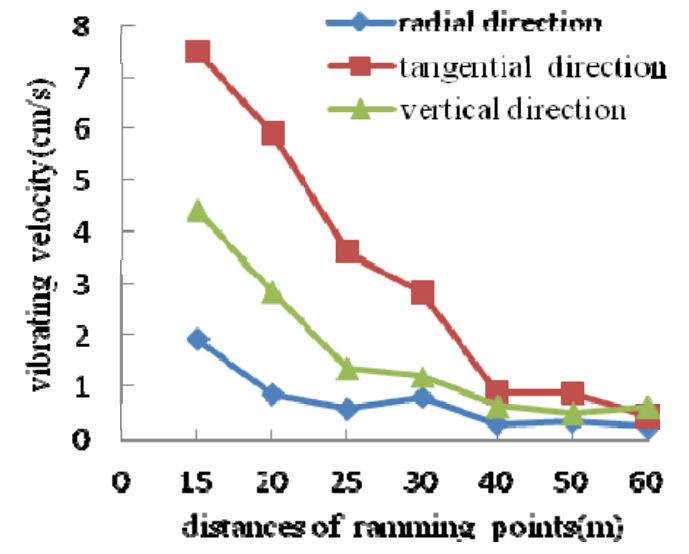

Fig.3 Vibrating velocity of $6000 \mathrm{kN} \cdot \mathrm{m}$

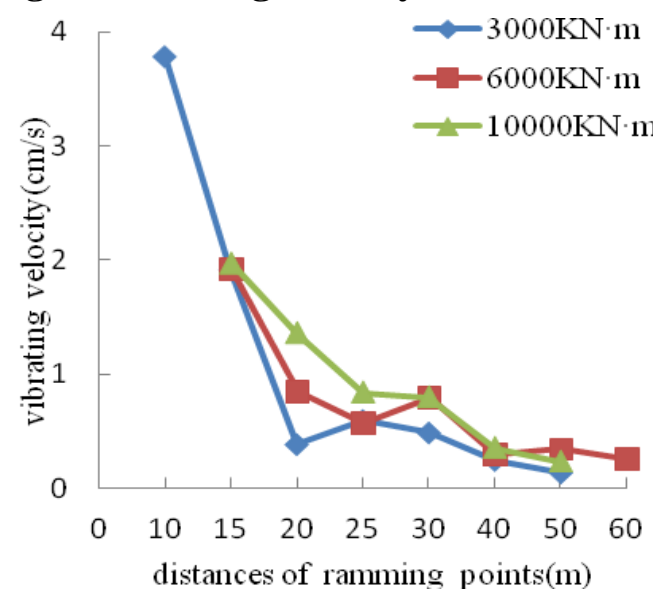

Fig. 5 Radial vibrating velocity of different ramming energy

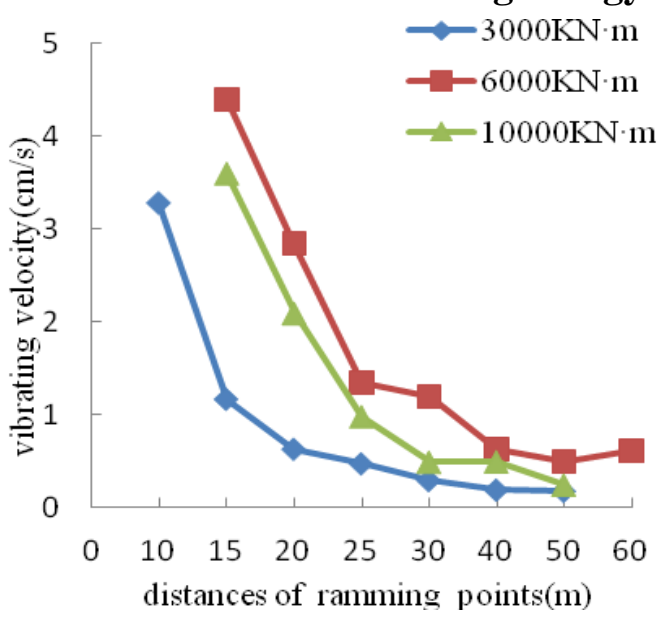

Fig. 7 Vertical vibrating velocity of different ramming energy

Testing results and analysis of rayleigh wave test. Rayleigh wave's velocity increases with the increase of the density of medium,after dynamic compaction, The porosity between soil particles decreases, compaction degree of Soil increases. Therefore, we can test reinforcement effect of dynamic compaction, through analysis of the change of rayleigh wave's velocity .The testing datas of rayleigh wave velocity before and after dynamic compaction are shown in Table 2, The percentage increase curves of rayleigh wave's velocity are shown in Fig.8.

Fig. 8 shows that the increasing of 0 to 2 meters depth's velocity after dynamic compaction is obvious in the first area.but for 0 to 2 meters depth of the second area and 0 to 3 meters depth of the third area, velocity is decreased compared with before ramming , and the larger the ramming energy is, 
the more obviously the velocity decreases. The reasons for this phenomenon is before ramming,because of earthwork car through,the surface soil is middle-dense state.when constructs,huge energy make the surface soil crush into soil grains,so its compactness decrease.

Table2 shows that for the first area, in the depth range of 0 to 6 metres, the average velocity increases from 138 to $154 \mathrm{~m} / \mathrm{s}$, increased rate is $12.1 \%$, the increased under the depth of 6 metres is unobvious,so the effective reinforcement depth is about 6 metres. In the same way, the effective reinforcement depths of the second and third area are about 9 and 12metres.

Table 2 Rayleigh wave velocity before and after dynamic compaction

\begin{tabular}{|c|c|c|c|c|c|c|}
\hline \multirow{2}{*}{ Depth(m) } & \multicolumn{2}{|c|}{$\begin{array}{c}\text { Rayleigh wave velocity before } \\
\text { dynamic compaction(m/s) }\end{array}$} & \multicolumn{3}{c|}{$\begin{array}{c}\text { Rayleigh wave velocity after } \\
\text { dynamic compaction(m/s) }\end{array}$} \\
\cline { 2 - 7 } & The 1st area & The2nd area & The 3rd area & The 1st area & The2nd area & The 3rd area \\
\hline $0-6$ & 138 & 151 & 162 & 154 & 158 & 171 \\
\hline $6-9$ & 152 & 148 & 164 & 150 & 167 & 229 \\
\hline $9-12$ & 158 & 153 & 161 & 159 & 159 & 208 \\
\hline
\end{tabular}

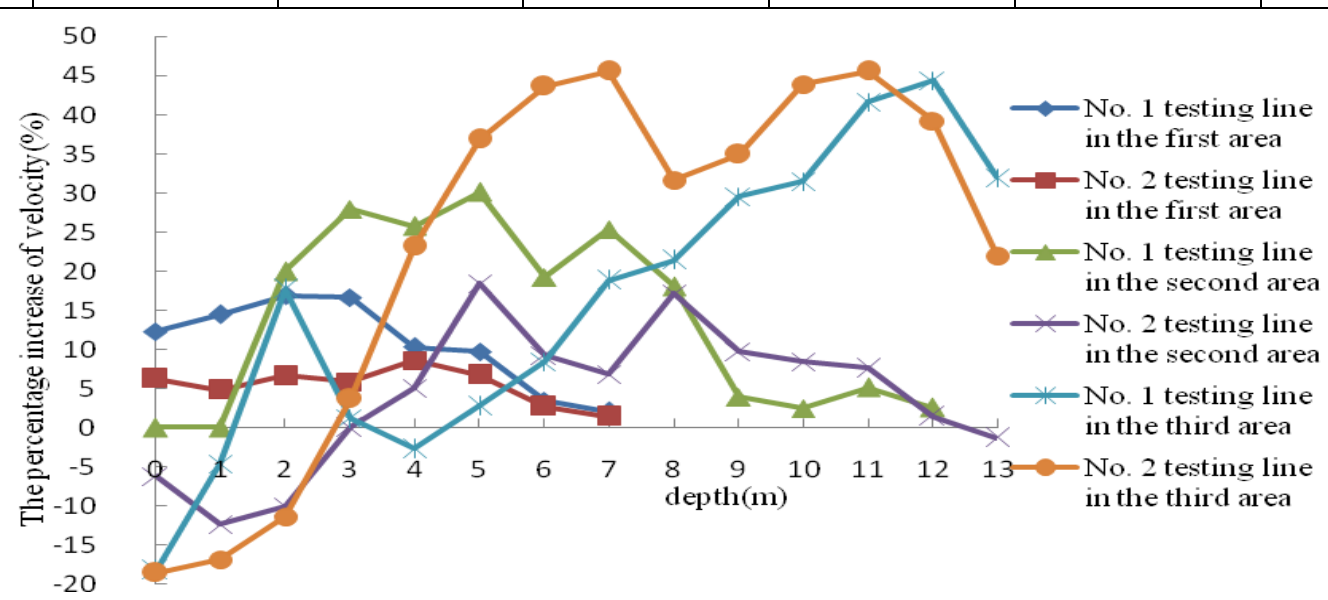

Fig.8 The percentage increase curves of rayleigh wave velocity Testing results and analysis of super-heavy dynamic pentration test..after dynamic compaction, choose two testing points of super-heavy dynamic pentration in each area. Also choosing three testing points of super-heavy dynamic pentration outside the area use as the before ramming's data. Through comparing datas, analyze the reinforcement effect of dynamic compaction. The testing datas of super-heavy dynamic pentration are shown in Table 3.

Table 3 The testing datas of super-heavy dynamic pentration

\begin{tabular}{|c|c|c|c|c|c|c|}
\hline \multirow{2}{*}{ category } & $\begin{array}{c}\text { Depth } \\
(\mathrm{m})\end{array}$ & \multicolumn{2}{|c|}{ Before ramming } & The 1st area & The 2nd area & The 3rd area \\
\cline { 3 - 6 } Gravel filling & $0-3$ & 3 & 6 & 6 & 8 \\
\cline { 2 - 6 } & $3-6$ & 3 & 7 & 9 & 12 \\
\cline { 2 - 6 } & $6-9$ & 5 & 5 & 5 & 7 \\
\hline Silt- Gravel filling & $9-12$ & 4 & 3 & 8 & 7 \\
\hline
\end{tabular}

Table 3 shows that the average ramming numbers of super-heavy dynamic pentration are improved compared with before,also the higher the ramming energy is, the larger the average ramming number is.Come to the conclusion, for this kind of gravel filling, high energy level of dynamic compaction can get a good reinforcement effect.

For the first area, The average ramming number of super-heavy dynamic pentration increases obviously in the depth range of 0 to 6 metres, the increased under the depth of 6 metres is unobvious, so the effective reinforcement depth is about 6 metres. In the same way, the effective reinforcement depths of the second and third area are about 9 and 12metres.

Correction coefficient calculation of menard formula. At present, Scholars[15,16] put forward many different calculation formulas of effective reinforcement depth, but the most commonly used is modified menard formula. Its expression is shown in type (1). 


$$
\mathrm{h}=a \sqrt{\frac{W H}{10}}
$$

In the formula: $\mathrm{h}$ - effective reinforcement depth (m); $\alpha$ - correction coefficient; $\mathrm{W}$ - rammer heavy $(\mathrm{KN}) ; \mathrm{H}$ - rammer falling distance $(\mathrm{m})$.

Synthetically, the effective reinforcement depths of 3000,6000 and $10000 \mathrm{kN} \cdot \mathrm{m}$ are about 6,9 and12 metres. Put the different ramming energy and its corresponding effective reinforcement depth into the formula (1),get the correction coefficients are $0.346,0.367,0.379$.The calculation results conform to 0.3 to 0.8 that recommended by related technical regulations,also accord with the literature[17] which recommend 0.37 to 0.41 for the ripped-rock filling foundation. So suggest the correction coefficient of menard formula is 0.35 to 0.41 for the deep gravel filling foundation.

Testing results and analysis of shallow plate loading test.After dynamic compaction, decorate three plate loading tests in each trial ramming area , all of maximum loadings are $400 \mathrm{kpa}$.The curves of loading and settlement are almost linear, no obvious turning points, don't reach breaking loadings. according to the $\mathrm{s} / \mathrm{b}=0.01$,determine the settlement is 14.14 millimeters, determine characteristic value of carrying capacity of foundation by the loading that 14.14 millimeters correspond to, but no more than half of the maximum loading.

The testing results show that the characteristic values of carrying capacity of the first , second and third area are 183,200 and $200 \mathrm{kPa}$, Can satisfy the requirements of design, come to the conclusion that the reinforcement effect of dynamic compaction is remarkable. Among ,the characteristic values of carrying capacity of the second and third area are larger than the first and settlements are obviously smaller than the first,so the reinforcement effects of the second and third area are better. the characteristic values of carrying capacity of the third trial ramming area is the same as the second, and settlements is smaller than the second, but the gap is unobvious.

\section{Conclusion}

For deep gravel filling foundation,porosity is larger, excess pore water pressure dissipates quickly, So can't consider the excess pore water pressure dissipation,can continuously construct.

The spread of vibration in the soil,tangential velacity is maximum,followed by the vertical velocity and the radial velocity is minimum.According to the blasting safety regulations, the safety distance of general civil construction is 20 to 40 meters,the safety distance of industrial and commercial buildings is 15 to 30 meters, advice the selection of safe distance should be subject to the last time ramming.

The rayleigh wave's velocity of the surface soil is decreased with high energy dynamic compaction.Also the larger the ramming energy is, the more obviously the velocity decreases. the reasons for this phenomenon is before dynamic compaction,because of earthwork car through,the surface soil is middle-dense state.when dynamic compaction constructs,huge energy makes the surface soil crush into soil grains,so its compactness and strengthing decrease.

The effective reinforcement depth of 3000,6000,10000kN•m are about $6,9,12$ metres, and the larger the ramming energy is, the better the reinforcement effect of deep soil is. Also advice the correction coefficient of menard formula is 0.35 to 0.41 , for the deep gravel filling foundation.

Through analyzing,get some conclusions, can provide a reference for construction parameters' choice about analogously dynamic compaction ,but doesn't get a better solutions about the reinforcement mechanism of dynamic compaction with high energy level, Still need further research.

\section{Acknowledgements}

This work was financially supported by the Hebei Natural Science Foundation Project (E2013403032). "Study on the mechanism of dynamic compaction and its application to dynamic response of unsaturated soil ". 


\section{References}

[1] Guanbao Ye, Yanbin Gao, Shulin Ye.Foundation treatment[M].The 3 edition. Beijing:China Building Industry Press,2009:40-43. (in chinese)

[2] Ming An. Construction Technology,2009,38(12): 107-109. (in chinese)

[3] Huahui Jin.Analysis on improvement effect of dynamic consolidation on foundation with gravelly soil and the forecast evaluation[D]. Chongqing: Chongqing University, 2012: 25-35. (in chinese).

[4] Yang Jiang,Wenbin Sun, Hejun Chai:Geotechnical Inverstigation\&Surveying, 2007, (12): 6-9. (in chinese)

[5] Weiquan Lin.Study on dynamic compaction mechanism and design parameters of the mountain stone fill foundation[D]. Wuhan:Wuhan University, 2012. (in chinese)

[6] Yankai Nian, Hongjiang Li, Qin Yang,etc: Rock and Soil Mechanics,2010,31(3): 689-694. (in chinese)

[7] Yankai Nian, Hongjiang Li, Qin Yang,etc: Chinese Journal of Geotechnical Engineering, 2009,31(1):139-144.(in chinese)

[8] WeihouShui, Tiehong Wang, Yaling Wang: Chinese Journal of Geotechnical Engineering,2006, 28(10): 1309-1312. (in chinese)

[9] Tiehong Wang,Weihou Shui,Yaling Wang: Chinese Journal of Geotechnical Engineering, 2005,27(7): 759-762. (in chinese)

[10] Shuaijun Zhao,Xin Lu,Sen Yang,etc:Logisical Engineering University, 2014,30(6): 12-16. (in chinese)

[11] Guanbao Ye,Xiaolong Zhang,Zhongqing Chen,etc: Geotechnacal Inverstigation\& Surveying, 2015(2):19-24.(in chinese)

[12] Changming Hu,Yuan Mei,Xueyan Wang:Rock and Soil Mechanics, 2012,33(10): 2903-2909. (in chinese)

[13] JGJ79-2012 Technical code for ground treatment of buliding[S].Beijing: China Building Industry Press,2012. (in chinese)

[14] Zongyuan Lin.Geotechnical processing manual[M].Beijing:China Building Industry Press, 2005:53-64. (in chinese)

[15] Dongwei Wang, Jin-hua Zheng, Wei-bin Li:West-Chian Exploration Engineering, 2005,07: 53-55. (in chinese)

[16] Pan J L,Selby A R:Advances in Engineering software,2002,33(7-10):631-640.

[17] Tiehong Wang, Weihou Shui, Yaling Wang,etc: Standardization of Engineering Construction, 2005(3):27-38. (in chinese) 